\title{
THE NOMINATIVE ASPECT OF THE LANGUAGE AND SPEECH UNITS
}

Suleymanova Nargiza Mardonovna

Senior teacher, Chair of English Lexicology and Stylistics

Samarkand State Institute of Foreign Languages, Uzbekistan

E mail: nargizasulimanova@gmail.com

\section{Crossref}

http://dx.doi.org/10.26739/2433-202x

Issue DOI http://dx.doi.org/10.26739/2433-202x-2017-9-9

Article DOI http://dx.doi.org/10.26739/2433-202x-2017-9-9-2

\begin{abstract}
This article deals with linguistics aspects of the speech units and its nominative features, also all units of language and their interrelations. It should be emphasized that the nominative units arising in the process of speech, including those expressed through a sentence, constitute a certain system that conforms essential laws that contain a synergistic power. However, if the meaning of the words necessitates the connection in the context of a syntactic context, nominally, this attitude serves to convey the motion of the body as a whole. The formation of speech (here refers to the external speech) is interrelated with two things, we see one of them in the word, whereas the second is seen in the syntactic structure. In other words, if the expression of thought is connected in content with the word, the use of words in speech requires a syntactic structure.
\end{abstract}

Keywords: speech units, nominatives, syntactic structure, morpheme, suffix.

\section{INTRODUCTION}

The term "nomination" means Latin (nominatio), nominal, denomination. The notion of nomination does not require explanation as to

Social science and humanities

Suleymanova N. 
the fact that today it has a theoretical basis and linguistic status. At the same time, this theory is studying the general principles of the formation of units of language. This is important because the nominative status of the linguistic units is extremely important in their application. The issue of translation of the language system units at the same time is very important now, because speech linguistics has just been scientifically substantiated and requires a language and language system in order for it to survive.

Lexical nomination and propositive nomination is closely related. Indeed, the lexical nomenclature necessitates the basic units of any language system, and the propositive nomination, in turn, is formed within the framework of the lexical units. In this regard, there is a close link between the propositive and the lexical categories.

The issue of the establishment of speech process is one of the critical priority researches of modern linguistics. Particularly, anthropocentric character of the current development of science linguistics has a drastic special ensuring position in the matter. Owing to the fact, the human factor plays an integral role, as it is not only the literal meaning of language, as well as the speech. We decided to mediate on this issue relying on the following idea of E. Benvenist found it suitable to apply to the following opinion: "The linguistic statues of the language of each speaker is closely connected with the necessity of a subject related to the event. Language is so connected to subjective issue, even at the same time that it will be a different question. Of course, task can't be called a different way to perform the task and could not be called the language»

E. Benvenist's model comments do not require an explanation. In fact, language is closely linked to the human factor. The human factor is the language of literal fortune. Therefore, the language system applied in practice, is also the human element -cannot be imagined from the speaker's concept. It indicates the language egocentric nature.

The following idea of E. Benvenist is worthy for consideration "The language is designed in such a way that allows each speaker, as he refers to himself as I like to assign his tongue entirely"

According to Saussure, linguistics (linguistics) is closely tied with a number of subjects. These subjects can sometimes give linguistics something and sometimes take something. Therefore, some Linguistics at times has difficulties to define the border between the two subjects and linguistics. However, despite being so involved in linguistics, disciplines should be bordered. For example, linguistics closely associated with the ethnography and philology, even though they all have their own goals and objectives. Social science and humanities 
Of course, language is closely related to the application of the language. However, the content of the concept of conversational speech activity is not connected. In current linguistics, it is necessary to study it in a different way. The concept of speech has general meaning; the speech activity of each speaker is connected with the activity of specific conversations. The famous linguist I.A. Zimnyaya emphasizes that language require product, the material, the speech is the formation of ideas through language. But the opinion of I. A. Zimnyaya wasn't accepted by E.C. Kubryakova. He notes that the speech engine that shapes the human mind that is not in accordance with the purpose of learning. In this case, E.S.Kubryakova gives the opinion that the product or material method (means) cannot be contradicted. In our view, there is some dilemma in an assessment of I.A.Zimnyaya. In fact, language is considered material for the formation of speech. However, this is not just material, but the speech engine compound. Therefore, the idea I.A. Zimnyaya speech language media said occurred seemed strange.

It should also be noted that the process of formation of speech, the speaker thought (feeling) opinions are applied. However, we need to understand it is abstract, because at the same time ready opinions are considered speaker's speech. When we have something to say suddenly, we cannot use products of contemplation. Firstly, we use verbal expression.

In fact, language, speech and language concepts interaction, is a very complicated process. The contents of all of these concepts lies in the center of the events associated with the expression. The basis of the first expression of language is the speech given in practice. Therefore, as a form of speech and speech activity, in our opinion, the goal does not appropriate. Since the formation of the idea in the first place, directly related to the contemplation of speaker, firstly, it composes as nonverbal and then that will move the speech and then find their expression. In other words, the ideas expressed in speech in the first, and then move the emphasis of the external appearance of his verbal. In this case S.D. Kasnelson denies the followings "Speech production - is the least of all the process of transferring the final act of thought or a mechanical translation of piecemeal - the internal code to the natural language". Thus, speech cannot be tool for the formation of the idea, the function of the object to be expressed in speech, and it always will be aimed at someone. However, this abstract characteristic of speech, it can be noticed its nonverbal formation, and has not pointed to a particular person.

It is characterized, under any circumstances concrete expression can be given through speech, and this is a very complex phenomenon, because, F.de Saussure expressed (signifier) called the name of that content integrity of this Social science and humanities 
process, and has its own status. Of course, it is necessary to understand the meaning of the term is expressed in place. In fact, Saussure called the second joints of these concepts through the language of signs (signified and signifier). However, the term is signifier in content is associated with the sign, at the same time we use it in a broad sense.

According to F. de Saussure, this term is used meaning that speech is copied from sign into language. More precisely, the idea "express given in practice" of Saussure actually be (sold means) was used. We see that this process is very complex and multi-faceted. Because at the same time reflect the formation of the opinion expressed in the language level, the talk will be required, the process will be a closely related, and the same way of thinking and speech patterns are difficult to imagine in isolation from each other. As the intelligence associated with the human factor, it is necessary to learn the speech, the formation of it in speaker's experience and language skills. At the same time, the language of the speaker system and its capabilities and how to use it can also play an important role.

In this case S.D.Katsnelson the following comments: language is poured into it, not as an integral structure with its inherent internal organization and fragmented, individual combatant elements are selected according to the needs expressed by thought and speech receiving their special construction. According to the idea of S.D.Katsnelson, the human brain with the mind is two aspects that are relatively autonomous. Each of them has its own memory; there are activities of knowledge in memory. In the speech, process there is a link between brain and language.

It is clear that, of each person's speech, lifestyle etc. has related knowledge and all of them are managed by human thinking. Contemplation has the dynamic nature of the process because it is not just a figure of speech, but there is always the influence of various evidence persisted with the action.

It is characteristic that contemplation is not given ready to people. It is associated with the development of the human mind. According to A. N. Leontevich, contemplation develops during the certain stage of human growth. That is why it can be considered the derivate (core) of practical activities of human being. E.S.Kubryakova thinks the same about the development of human language and mentions that the development of human activity is derivate. However, the concept of the derivative must be interpreted as substance in a broad sense, because the derivative concept is used because of the derivation. At the same time, the process of formation of speech the practical activity substance is meant.

Social science and humanities

Suleymanova $\mathbf{N}$. 
The formation of the speech associated with the formation of human thought and the first stage of nonverbal characteristic is formed in the internal speech is recognized by nearly all the linguists. However, the issue of transferring of inner speech to outer speech section the different opinions of linguistic can be noticed. According to idea of L.S. Vigotskiy ready result of contemplation which is appropriate for speech can't be discussed. The formation of speech is a very complex process. He also noted that, according to an internal speech, has its specific aspects, firstly from idea it turns into meaning, from the meaning it transfers into inner speech evidence. In addition, meanwhile the inner meaning of speech formed the internal interconnectivity has an important role. After that, the progress from internal word to the external word will happen and in this process is uncertain, abstract ideas are directed to be a verbal expression.

Agreeing with the idea of L.S.Vigotskiy also, it can be considered that it is impossible to move directly to the meaning from the inner speech, and from meaning to the word.

From our point of view, from the meaning can be transferred to the conception, and then it will be possible to make progress, with the help of conjunctions internal speech can be shifted into external one.

It should also be noted that the internal speech differs from external speech according to its abstract aspects. Furthermore, internal speech cannot be clearly aimed to the listener. External speech has always its listener. In this process, the speaker should consider the level of the listener, in the environment of speech clearness and unclearness of the listener ought to be considered. This, in turn, in dairy agenda external speech should choose the expressions for the real situation. In fact, any expression of speech situation will be accomplished through the use of certain lexical material. Moreover, in an internal speech imagine the events of the incident are not existed. External speech cannot be happened in our world. Therefore, the syntax of external speech differentiates from internal speech syntax, because the internal speech is for the speaker and external speech pointed at someone.

The interconnection between language and speech or speech activity is very complicated process. The phenomenon is related to the idea that the description lies at the centre of all these notions. According to deep meaning, nominatives belong to a word, a language unit. Obviously, objects, items and events in existence are named with words, but the nature of a word is very complex. It can be observed not only in its denoting function, but also in nominative nature. Especially, compound words are of special importance in this case. In order to prove this idea, let us pay attention to the words pakhta Social science and humanities

Suleymanova $\mathbf{N}$. 
(cotton) and pakhtakor (farmer, a man who picks cottons). It can be seen that the word pakhta (cotton) actually has the nominative characteristic, as it is a root word. Meanwhile, it should also be said that the nominative feature in this word is permanent and does not depend on any inner or outer factors. Yet, another situation happens with the word pakhtakor (farmer, a man who picks cottons). It has internal and external nominative features, in other words, it possesses primary and secondary characteristically nominative explanations. Primary nominatives can be observed in the root morpheme parts - cotton and pick - and secondary nominatives are in general connected with the compound word (cotton picker) itself, which was formed with the help of the suffix -er. Nevertheless, the nominative feature of the word cotton picker is also permanent because it has its own place and significance in the lexical composition of a language.

As it was mentioned before, the nominative feature of a language unit is the root morpheme almost all root morphemes, except for ones in dependent word frames, have this characteristic, but it is not appropriate for affix morphemes. Since, according to their functional peculiarities, they are considered as the tools to form secondary nominative features. Therefore, it is hard to agree with the following idea of Solntsev: "All language and speech units, which are double-sided (both descriptive and described) have a nominative feature"

Certainly, all the language units possess a descriptive and described nature. It can be marked with morphemes as well. However, it is impossible to consider affix morphemes as nominative units. These morphemes are not of nominative character but of an associative nature. Thus, a particular affix morpheme can serve for the formation of several words: worker, player, teacher, writer, hunter, etc.

Besides that, in some languages, auxiliary words do not have a nominative aspect either. For instance, in Turkic languages, conjunctions and prepositions can hardly be called as lexically meaningful. Even if they have lexical meaning to some extent, it will be too abstract. For this reason, it is better to study them as morphemes. However, it should also be said that in some research, auxiliary words- prepositions in particular- are regarded as language units with lexical meanings. Greater information on it is given in V.V.Burlakova's monograph "The basics of word combination structures in Modern English".

Certainly, prepositions may denote a weak lexical meaning, but it cannot be cause for considering the preposition as nominative unit, because it 
is not the specialized language unit, which describes the term of an object or an event.

According to nominative features among language units, set expressions and phrases possess particular significance since both of them have nominative characteristics. Although the components of these combinations are made up of words, these words do not serve for the description of independent nominative features, but the formation of nominative aspects, which are generated by the combination.

The nominative features of set expressions and phrases are also permanent, because they exist in lexical composition of the language peculiarly in ready form. This kind of situation can be observed with compound words as well. Meanwhile, word components in complex indicate a nominative aspect. In general, the nominative feature in all compound words is connected with their inner structures. Here, the development of meaning plays the main role; indeed, a new meaning appears based on a particular one.

Speech units differ from language units according to their distinctive nominative characteristics. The difference between them can be observed firstly in temporary or constant nature of nominative meaning. In other words, nominative meanings of speech units are not steady but transitory. Certainly, these units do not exist in set forms in language, they configure in speech. A good example of this can be free word combinations. The meanings of these combinations are formed in a sentence, but denote different meanings every time. It can be clearly observed in noun phrases: le livre de Pierre (the book of Pierre), the garden of the university. However, verb phrases indicate both nominative feature and communicative characteristics: to do the task, to live in countryside, to read a book, to study at university.

Surely, these combinations are out of speech and they are only nominative units. However, if they are used in speech, they denote communicative meaning as well: (he) did the task, (he) is reading a book, (he) studies at university. According to this point of view, noun phrases, formed in speech, can be called pure nominative units and verb phrases can be called nominative-communicative units.

Nominative-communicative features of speech units may clearly be observed in sentence, because a sentence indicates not only declarative meaning but also considered as the term of given information in reality. In order to prove this, let us take the following examples: Tom opened the door and the road became wide. In these examples, both sentences have communicative functions. Moreover, they denote nominative meanings. It Social science and humanities

Suleymanova $\mathbf{N}$. 
can also be observed in the following syntactical structures that he opened it with a key and the road was widened, which can be imagined as the term of the expression of the information. However, previously mentioned, expressed nominative meanings do not present constant characteristics. If the given sentences are used in speech, they denote the appropriate meanings, but for the other speech situations, these meanings are inappropriate, as they express other distinctive meanings. Therefore, the nominative features of speech units are said to have a transitory nature.

\section{CONCLUSION}

In conclusion, nominative characteristics of language units are constant whereas this aspect is temporary for speech units. In other words, the nominative feature is the primary and the communicative feature is the secondary characteristics of language units. We believe that when expressing a message in the process of speech, if one approaches the description of an issue from the point of view of internal and external speech, to transfer the product of thinking to speech firstly, there is a need for a word or else in lexical material, and then the syntactic structure is chosen. However, if we consider the essence of the problem only from the point of view of external speech, the choice of the syntactic structure acquires a primary meaning. In this case, the schemes of sentences existing in the human consciousness are used. Consequently, it is possible to emphasize the same ratio of speech formation to the choice of lexical material as well as to the choice of the syntactic structure. 


\section{References}

1. Benvenist E. General linguistics. - M., 1974, 295p.

2. Paducheva E.V. Egocentric valence and deconstruction of speaking / Questions language, No. 3, 2011. - .3p.

3. E.A.Popova «Man as a fundamental value of modern linguistics «Philology» 2002, № 3. 69 p.

4. Saussure F.de Works of the linguistics-M, 1997, 57p.

5. Norman B.Y. the Syntax of the speech activity -Minsk, 1978, 3p.

6. E.A.Zimnya Psychological aspects of teaching speaking in a foreign language. - M., 1978, 23p.

7. S.D.Kanselson "Speech cogitative process" // Linguistics questions, 1984, No.6, page 4.

8. E.S.Kurbyakova Nominative aspect of speech activity-M. 1986-23 p.

9. L.S.Vigotskiy "Thinking and speech" Gathered essay-M. p 11.-p.12-13

10. Rassel B. Logic and Knowledge. - London, 1956, 382p. 